Butwal Campus Journal, Vol. 3, No. 1: 61-70, July 2020

Research Management Cell, Butwal Multiple Campus, Tribhuvan University, Nepal

\title{
AGE: A DEMOGRAPHIC FACTOR MATTERS TO E-LEARNING IN NEPAL
}

\author{
Durga Bhusal* \\ *Assistant Professor, Butwal Multiple Campus, Butwal, TU
}

Article History: Received 15 May 2020; Reviewed 02 June 2020; Revised 30 June 2020; Accepted 09 July 2020

\begin{abstract}
COVID-19 worldwide pandemic has created the new environment of ability transformation of teachers from organizing traditional classroom learning to manage behavior of their students in electronic learning demanding skill of new technology. It is challenging to achieve positive educational outcomes in Nepal through sound behavior management establishing the environmental context that makes the good instruction and highly effective learning possible. Highly effective instruction reduces, but does not eliminate, students' behavior problems in both traditional class room and e-learning management. The purpose of this paper is to provide information related to effectiveness of e-learning to improve positive outcomes of teaching regarding educational demographics. Various intellectual properties are reviewed to fulfill the purpose of this paper. Teachers able to break resistance of new technology would be only effective to implement strategies of e-learning and then can appropriately manage the behavior of targeted group of students is crux of this study.
\end{abstract}

Keywords: age - e-learning - Nepal

\section{INTRODUCTION}

Innate collections of behavior do not decorate the people but they must learn from environment where they acquire new response patterns through direct involvement or by observation. Genetics and hormones affect the acquisition process of knowledge. Behavior of people in terms of extreme hereditarians and environmentalists, whether it is experimental or physiological, is not easily separable. Forthcoming values of remote consequences motivate 
humans with anticipatory thought encouraging to bear current behavior (Bandura, 1977). COVID-19, the worldwide pandemic, has created the new situation in Nepal even on the areas of formal learning occurring through gathering in rush. Distance making and gathering in the old infrastructural basement has become almost impossible for the institutional managers. The door of e-learning is opening as the alternative tool to run the academic session. This complex scenario has compelled those who are favorable in traditional class room teaching learning activities to enter in the undesired e-learning settings. Access, skills, authenticity, satisfaction, and technical support have become the important factors to make the e-learning successful. It seems in Nepal of weak e-learning setting strength that some energetic manpower of middleaged group and newer generation are enjoying the virtual meetings and classes but older adults are appearing to the e-learning setting with the intention of escaping from it.

In the past, near of commencement of computer discovery, common humans were roaming into a propaganda that computer knows everything hiding the reality that computer is the manmade machine. Even today, the complicated and wonder works done by computer in easier way pointing out its superiority over human. The student of $21^{\text {st }}$ century without the skill of computer is understood as dull one. Based on 1920s and 30s as the period of active discoveries and new theories for the scientific disciplines, the decade of $40 \mathrm{~s}$, after the Atanasoff Berry Computer, later termed as the ABC, was constructed at Iowa State University during 1939-1942 by Dr. John Vincent Atanasoff-professor of physics, and his graduate student-Clifford Berry, computing business was begun, but commercially in 50s. Introduction of the internet in $60 \mathrm{~s}$, networking and word processors in $70 \mathrm{~s}$, and the graphical user interface came in 80 s show that we have more new technologies emerging so fast.

Both learner level and teacher level characteristics are equally important to online success. The students of face-to-face learning environments engaged in online learning feel fewer opportunities to interact with their teachers and peers. Lack of base line levels interaction does not allow the online teaching learning attempts to be academically sound. Teacher level online teaching demands the mentor with the skill of well-versed instructional practices and virtual management techniques (Zhang \& Lin, 2020). Recommendations for special education to improve achievement of at-risk students, and ability of teachers to manage classroom behavior are in directly proportional relation. Economically disadvantaged students' problem that is disruptive behavior needs the ability of teachers to prevent or address the problem (Oliver \& Reschly, 2007). Inappropriate assignment, inadequate preparation, inadequate professional development etc. are major contributing factors to the classroom as 
well as virtual management problems. Political involvement in profession, insufficient training for teacher, classes with large proportion of at-risk students, unexpected disruptive behavior of students, not responding or more reactive to students' inappropriate behavior etc. bring the difficulties in teaching. Classroom environment, rules and routines of classroom, supervision of students' engagement, and encouragement of appropriate behaviors of students, and collection and usage of data to modify classroom management procedures as needed are the requirements to include in a comprehensive approach for effective classroom management.

\section{METHODS AND MATERIALS}

This study uses the Servage (2005) for the definition of e-learning which he has got from US Report (2002) by the Commission on Technology and Adult Learning that refers to instructional content or learning experiences delivered or enabled by electronic technology (Fleming, Becker, \& Newton, 2017). Much of the reviews has been occurred in relation to elearning has been undertaken in this study of educational context. Field notes, and interviews with a university professor, a school teacher, and a university student are also used as source of knowledge in this study. No any statistical tools are used to analyze the data used in this descriptive study.

\section{DISCUSSION}

Between two kinds of e-learning on the basis of availability of mentors and learners, one, 'Asynchronous E-learning' facilitated by the web, email and discussion board like media, is flexible that support teachers and learners when they are not online at the same time, but does not provide the opportunity of instant interaction, and another, 'Synchronous E-learning' facilitated by online chat and video conferencing like media, is strict to demand the mentor and learners at online at the same time which provides the opportunity of instant communication with others to simplify the hardship created in the teaching-learning process. (Shakya, Sharma, \& Thapa, 2017).

\section{Comparison between the traditional classroom learning and electronic learning}

Learning line never ends and it is life long process to be updated with fast growing technology. Classroom learning style exercising over centuries till today requires books, notebooks, lecture notes, students and teacher in the same class room, explanation of content 
by the teacher, listening and writing by students, and interaction. Two-way communication in face-to-face presence of learner and instructor contribute learner to feel more comfortable asking the problem faced during learning process to acquire knowledge and academic skill. Electronic learning style which is the result of advancement of technology to the education circle whereby we've been introduced to use it. E-learning demands internet facility to use web gateway, e-book, video, audio and the like electronic means to get the learning materials across the students.

\section{Empirical review on age and e-learning}

The study of Schodt (2005) delivers a result of correlation between gender regardless of age and level of learning where the classroom performance of males has higher level than female students in the setups where mentors used no technology, but female students showed higher levels initial affect in classroom scenarios where instructors used moderate amounts of technology. Sluggish rate is fruitful for older people to perceptual learning rather than the rate for younger ones (Gilbert, 1996). Mungania (2003) finds the instructive listeners of e-learning people in his study comprising 80 percent of the polled respondents lower than the age of 45 years. Age, an unspoken construct targeting old age people, is often raised as a potential inhibitor for the adoption of new technology even though it helps to ease their lives. Chung, Park, Wang, Fulk, \& McLaughlin (2010) found significant negative relationships between age and internet self-efficacy, perceived usefulness, perceived quality of online community and intention to use. Chawla and Joshi (2012) found that those aged 25 and under were more likely to have a favorable perception of e-learning than those over 25 years. Chu (2010) also found that older e-learning participants may require more support than their younger counterparts. Rizzuto (2011), found that older workers react positively to technological innovations including e-learning. Personal perceptions about an e-learning experience can influence attitudes and impact on whether learners intend to use e-learning in the future (Sun, Tsai, Finger, Chen, \& Yeh, 2008). Acknowledging Rogers and Shoemaker (1971).

Fleming, Becker, and Newton (2017) mention the definition of complexity as "the degree to which an innovation is perceived as relatively difficult to understand and use". Teo and Wong (2013) agree that perceived ease of use is a predictor of user satisfaction and influences intention for future use. In the case of e-learning, beyond characteristics of the elearning course and characteristics of the user, acceptance and future use has also been argued to rely on the availability of technical support (Williams, 2002). A lack of technical expertise to support the e-learning initiative, has been cited as one of the most important barriers to 
overcome in relation to e-learning (Black, Beck, Dawson, Jinks, \& DiPietro, 2007; Selim, 2007). Responsibilities pertinent to the real biosphere are associated with the trustworthy learning (Herrington, Oliver, \& Reeves, 2003).

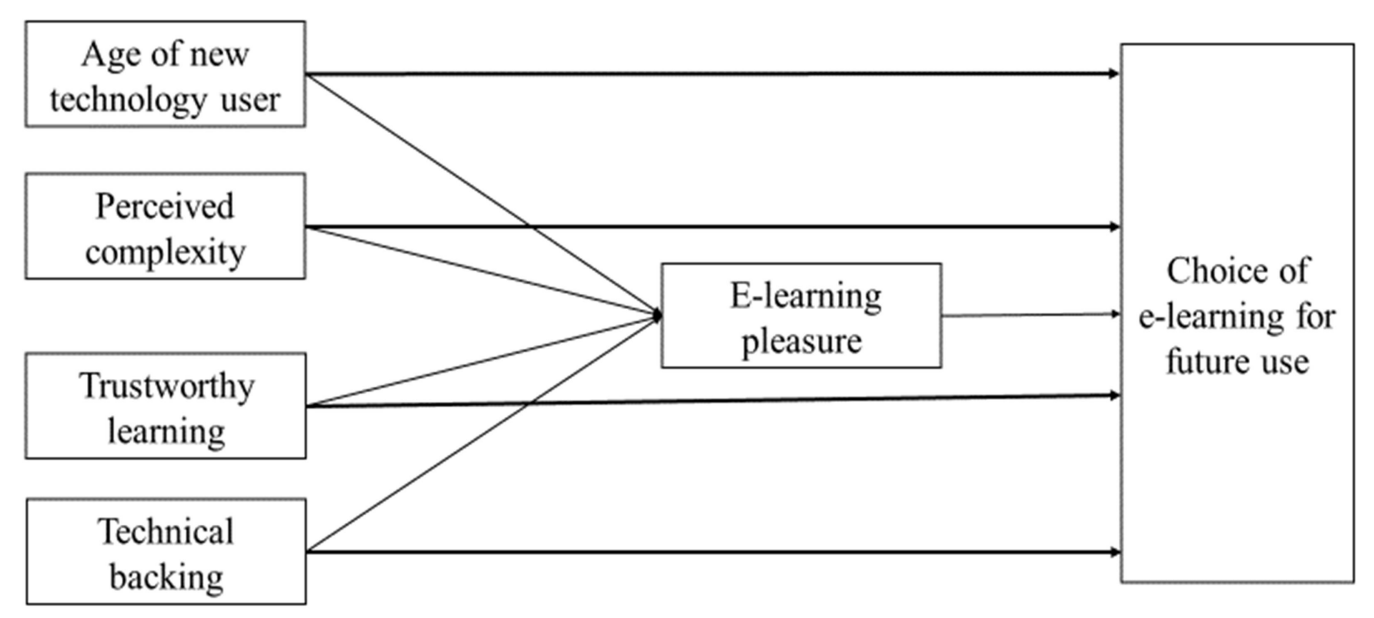

Source: Adopted from Julie Fleming, Karen Becker and Cameron Newton (2017) mentioned in "Factors for successful e-learning: Does age matters?" page 81

Figure 1: Factors for choice of e-learning

\section{The evolution e-learning method in education sector}

Old-style methods of learning may swiftly become old-fashioned and ineffective due to rapid advancement of technology as learners cannot adapt with complex work environment of learning process to be appropriate nowadays even though traditional learning methods still work best and used in many segments of market areas. For this reason, people must be able to learn from Advancement of new innovative leaning methods compelled the people must be able to learn through new technology in order to stay ahead in race of competition. According to Cohen (1997) introducing the technology into classrooms has made it possible for the learners to incline four times more effective than traditional educational approaches. Charp and Sylvia (2003) mention that the students' learning process and the teachers' delivery process is more effective in technology-based than that in traditional classroom. They also emphasized that the technology-based education can improve learning and teaching 
experiences, increase interaction with others who are geographically remote and also provide more affluent communication opportunities (Islam, 2011).

Political involvement in education should have in making policies to guide the nation, but, in Nepal, recruitments on the basis of political ideology rather than capability, movement of students for political benefit rather than their own real rights have leading to create the doubt to understand role of education if it is able to improve the lives of grass-root people. Unexpected behavior of students created in class room due to politics of students' organizations can be solved by trick technique. Experience which is directly related with professional time is that ornament of teacher that collapses inappropriate assignment, inadequate preparation and inadequate professional development like deformities of teaching. Not responding or over reactive teacher to students is the professional devastating characteristic since it discourages the students who want to raise the question for discussion which help to solve problem and make knowledge behavioral. Teacher with only good knowledge may have to face unexpected problems during teaching if he/she/third lacks to organize knowledge for the trick since students also want entertained and relax learning environment. Unexpected disruptive behavior of students discourages the teacher lacking sufficient teaching experiences. Large proportion of students creates unnecessary noise from students' site that disturbs the attentive environment of genuine students and needs loud sound from teacher site that may create health problem in teacher. Training improves the teacher as confident teacher for better and skillful performance to manage classroom. Structuring or physical arrangement of classroom environment helps to ease traffic flow, minimize distractions, and provide teachers with good access to students in order to respond to their questions and better control behavior. Efficient use of classroom time, including transitions between various classroom activities, motivates the students to be disciplined, punctual, and responsible. Rules and routines, if worded positively and performed effectively to describe and establish the expected behavior, help to prevent problem behavior, and the use of positive, preventive, and proactive strategies rather than punishment are effective to enhance quality of life both by preventing student behavior problems and decreasing teacher stress (Emmer \& Stongh, 2001). Supervision of students' engagement helps to prevent the students from probable wrong doing. Encouragement of appropriate behaviors of students contributes to develop write doing interest. 


\section{The field notes and interviews}

Technology in teaching is being influential after the outbreak of COVID-19, a worldwide pandemic. Nepal being secure from this pandemic had not possible. Teachinglearning activities during this situation demand innovative technology. Different personalities of different age group have expressed their experiences about e-learning in my interview as follows:

One of the professors of the university with 50 years of age says:

I am personally very interested in computers and love technology, but in the sense of teaching because of my long old fashion teaching experience, I could not learn new technology much. I need only the skill of slide preparation and presentation. All the students in a country like Nepal could not be addressed through e-learning.

Another 35 years school teacher expresses about the e-learning

Technology helps us to receive and deliver knowledge in an easy and interesting way. I, personally, like the e-teaching style because I have done a course of e-teaching in which my future was attached. COVID-19 brought this opportunity and basically, all of my classes are moving through this mode.

One of the university students of 23 years old says

I want to be tested because of the world's scenario where humans need to be influential in the competitive market of this twenty-first century.

Field note points out the effect of age in teacher-teacher interactions which were different than in a regular classroom, and students' interest was that the technological capability of teacher must be competitive.

\section{E-learning challenges in Nepal}

There are convinced encounters associated with the E-learning in the present context of Nepal. These challenges should be overcome to make the e-learning environment enjoyable as the alternative method of learning. The conventional mind set of learning may derive reasonable segment of challenges applying the e-learning methods like virtual classes through radio, television and the internet. If e-learning system as such is implemented without consideration of people's needs and their income level, social inequality will be prevalent 
because of affordability of small group of rich people, and the system sustain no longer (Singh, 2020).

Age and skilled manpower: Management of older employees in the formal service who feel ease in the traditional system.

E-learning motivational psychology: Motivational training to avoid the lack of beliefs about technological adaptation for the existing lifestyle.

Availability of technology: Providing required ICT devices where poverty is leading not to afford the technology in a large number of populations.

Availability of internet service: Increasing capability of service providers who have not achieved the coverage of whole Nepal and assurance of quality service in provided areas.

Availability of electricity: Showing responsibility on the destruction of electronic devices through the accidental over-voltage problem, and maintaining smooth power distribution for all.

Affordable cost: Management of affordable cost of the advanced development of technology in this 21 st century for common Nepalese people in terms of procurement and paying rental charge of internet and electricity.

Language and e-learning materials: Providing the internet materials adequate in Nepali language where English language is dominant which is not easy to command for Nepalese e-learner.

Training and technical support: Management of skilled manpower for technical support to avoid the fear of e-learner to handle the electronic device due to little knowledge.

\section{CONCLUSION}

The e-learning participants with older age may need more technological backing than their younger counterparts. The relation between age and satisfaction establishes negatively which means that the higher the age of the e-learners, the lesser the satisfaction they obtained. But the separation of particular age limit adapting with the new technology is almost impossible although children adapt easily. E-learning has become an effective and complex tool in current educational system which is mostly influenced by effects of COVID-19 in terms of teaching learning activities, although it has somehow positive effects on the learning process of student and teaching process of teachers. Electronic learning system can deliver alternative and updated information of knowledge that may not be obtained in the traditional 
classroom-based instruction in equal basis. The impact of e-learning may be extended to other sectors like in social work. E-learning offers potential benefits for social workers whatever their age because of its flexible access on time and place. It also widens accessibility to learning opportunities through access. Information literacy like related facts on social work, writing and presentation skills can be gained. It also brings an improved motivation and engagement through the new things to be learned. Through e-learning, social workers can easily assess, monitor and record their learning progress. Hence, this will make them aware of the strengths and weakness they have and what they will need to have a strong background in social care.

Smart and effective teachers are able to implement strategies appropriately to manage class wide behavior, the behavior of targeted group of students, and the behavior of individual student as part of the comprehensive learning management plan. They also understand that no single strategy is effective for every student at all times and in all contexts. Effective classroom management requires teachers to be adept at employing multiple strategies and to be skilled at recognizing when current strategies are ineffective and modifications are needed.

\section{REFERENCES}

Bandura, A. (1977). Social learning theory. Stanford University, Prentice-Hall, Englewood Cliffs, New Jersey 07632

Black, E. W., Beck, D., Dawson, K., Jinks, S. \& DiPietro, M. (2007). Considering implementation and use in the adoption of an LMS in online and blended learning environments. Tech Trends, 51(2), 35-53.

Chawla, D., \& Joshi, H. (2012). E-learning perception and its relationship with demographic variables: a factor analysis approach, International Journal of Information and Communication Technology Education, 8 (4), 105-118.

Chu, R. J. C. (2010). How family support and internet self-efficacy influence the effects of elearning among higher aged adults: analyses of gender and age differences, Computers \& Education, 55(1), 255-264.

Chung, J. E., Park, N., Wang, H., Fulk, J., \& McLaughlin, M. (2010). Age differences in perceptions of online community participation among non-users: an extension of the technology acceptance model, Computers in Human Behavior, 26(6), 1674-1684.

Cohen, V. L. (1997). Learning styles in a technology-rich environment. Journal of Research on Computing in Education, 29(4), 338-350. https://doi.org/10.1080/08886504.1997.10782203 
Emmer, E. T., \& Stongh, L. M. (2001). Classroom management: A critical part of educational psychology, with implications for teacher education. Educational Psychologist, 36(2), 3-112.

Fleming, J., Becker, K., \& Newton, C. (2017). Factors for successful e-learning: does age matter? Education + Training, 59(1), 76-89. https://doi.org/10.1108/et-07-2015-0057

Herrington, J., Oliver, R., \& Reeves, T.C. (2003). Patterns of engagement in authentic online learning environments. Australasian Journal of Educational Technology, 19(1), 59-71.

Islam, M. (2011). Effect of demographic factors on e-learning effectiveness in a higher learning Institution in Malaysia. International Education Studies, 4(1), 112-121.

Mungania, P. (2003). Seven E-learning barriers facing employees: Executive summary of dissertation. University of Louisville (Online), USA, 21-25.

Oliver R. M., \& Reschly D. J. (2007). Effective classroom management: Teacher preparation and professional development. National comprehensive centre for teacher quality, Vanderbilt University, Washington, DC.

Rizzuto, T. E. (2011). Age and technology innovation in the workplace: Does work context matter? Computers in Human Behavior, 27(5), 1612-1620.

Shakya, S., Sharma, G., \& Thapa, K. B. (2017). State education system with E-learning in Nepal: Impact and challenges. Journal of the Institute of Engineering, 13(1), 10-19.

Selim, H. M. (2007). Critical success factors for e-learning acceptance: confirmatory factor models, Computers \& Education, 49(2), 396-413.

Servage, L. (2005). Strategizing for workplace e-learning: some critical considerations. Journal of Workplace Learning, 17(5/6), 304-317.

Singh, S. K. (2020). Scope and challenges of e-learning in Nepalese context. Retrieved in 2020/06/01 from https://edusanjal.com/blog/scope-and-challenges-e-learning/

Sun, P. C., Tsai, R. J., Finger, G., Chen, Y. Y., \& Yeh, D. (2008). What drives a successful elearning? An empirical investigation of the critical factors influencing learner satisfaction. Computers \& Education, 50(4), 1183-1202.

Teo, T., \& Wong, S. L. (2013). Modeling key drivers of e-learning satisfaction among student teachers. Journal of Educational Computing Research, 48(1), 71-95.

Williams, P. (2002). The learning web: The development, implementation and evaluation of internet-based undergraduate materials for the teaching of key skills. Active Learning in Higher Education, 3(1), 40-53.

Zhang, Y., \& Lin, C.-H. (2020). Student interaction and the role of the teacher in a state virtual high school: What predicts online learning satisfaction? Technology, Pedagogy and Education, 29(1), 57-71. https://doi.org/10.1080/1475939X.2019.1694061 